\title{
Education-Job Mismatch among Graduates of Administrative Staff: A Case Study of University of Gujrat
}

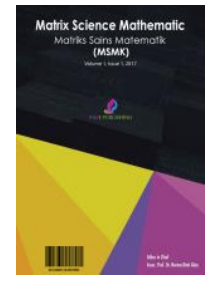

Amna Qadeer ${ }^{1}$ and Khadija Fatima ${ }^{1^{*}}$

${ }^{1}$ Department of Statistics, University of Gujrat, Gujrat, Pakistan

This is an open access article distributed under the Creative Commons Attribution License, which permits unrestricted use, distribution, and reproduction in any medium, provided the original work is properly cited

\section{ARTICLE DETAILS}

Article history:

Received 28 September 2016 Accepted 12 December 2016 Available online 16 January 2017

Keywords:

Job Mismatch, Multilayer Perceptron Neural Network, Graduates, Classification.

\section{ABSTRACT}

In this study, an effort is made to classify the significant aspect of mismatch between education and job among graduates. The exactness of the equivalent between employee's abilities, talents, skills and those demanded by the institutes, rarely tackled in the literature. Freeman was the former who elevated his apprehensions above this extension in his study named 'Overeducated Americans'. The data of 220 respondents collected from the administrative staff, lab assistants from the University of Gujrat using well-structured questionnaire. The Multilayer Perceptron Neural Network technique has been used for analysis purpose. Results revealed that overall correct classification is almost $100 \%$ on the basis of limited resources, family responsibility, Family forced, job advertisement and distance from work.

\section{INTRODUCTION}

The exactness of the match between employee's education and work has gained the interest of economists over the last two decades in European countries. However, Pakistan is observing the identical dilemma since a coon's age like other countries and no straight research on profession and academic is conceded on a huge level. Anyhow, awareness is flourished regarding to this issue. A former who elevated his apprehensions above this extension in his study named 'Overeducated Americans' (Freeman, 1976). Since from the late 1980s, the study on irrelevant jobs boomed in US plus within more advanced countries. A range of studies have documented numerous circumstances and aspect with the purpose to discover a range of components of job-education mismatch. There are different definitions of education and jobs mismatch defined by different people. Mismatch between education and work is generally known as irrelevant job. The achieved qualification of the employees can be lesser or superior than the mandatory education regarding to their prospected jobs. The employees are considered to be inequitable in education when the above-mentioned phenomenon occurs (Green and McIntosh, 2002; Lourdes et al., 2005). According to Reddy told University World News. "At opening point, you look forward to a bachelor having definite talents for instance transmission, capability toward English as well as effort like a squad and fundamental computer awareness. These well-defined abilities are not common now a day which causes mismatch between education and job. Job discrepancy occurs with the condition that the growing rank of qualification is not coordinated with the jobs (Freeman, 1976). This shows the inefficiency among the employee's obtained rank of qualification and the rank of qualification necessary for their jobs. Employees are treated as over educated whenever the rank of their gained education is upper than the rank of education demanded for their work. In opposite direction, they are treated as under education if the rank of their gained education is lower than the rank of education demanded for their work. As a result, over education and under education are taken as two qualification divergence variables. The range of factors which are provoking the job discrepancy accompanying the meager rank of instruction regarding to different job spaces, organizational hurdles, geological hurdles, background or gender and etc. Different social and anthropological components and traditions are also noticed like the major a restraint for the female's workers (Nazli, 2004). The gender difference is very high gap is still high linked with financial skewed distribution in terms of financial region and rank (GoP, 2007). Economists and Sociologists considered the occurrence of education-job mismatch as a genuine impact. This impact captivates along its related social and economic worth by personage, organization and state rank. By personage level, the occurrence of education-job mismatch causes to decline the borderline output of the person. Owing to this declination the expected earnings diverge over the nations. On the organization level, profession divergence is connected by means of lesser production and inferior rank of profession participation. Thus, the quick learning development arrangements perhaps not give in the most wanted genuine financial profits (Budria and Egido, 2007). 


\section{Literature Review}

A research performed to find a job mismatch and assessment of events impact on graduate income in Pakistan (Farooq, 2015). He had divided the job mismatch into three types qualification-job mismatch, skill mismatch and field of study and job mismatch. By statistical analysis he found that the irrelevant graduates are $11.3 \%$ and the slightly related employment in their field of study subjects $13.8 \%$. They found that overqualified graduates have faced wages penalty. He found that wages of graduates improved by good field of study and job matches. Some of researcher carried out a research to investigate the consequence of education and job mismatches (Badillo and Vila, 2013). For this purpose, they used Spanish data from the European Community Household Panel (ECHP) survey for the year 2001. The statistical analysis showed that education and skill mismatches are dimly associated in the Spanish labor market. They also found that the mismatch of jobs come out as principal source of worker's job satisfaction. However, the skills and mismatch of education have a negative impact on wages. Scientist conducted a research using a different method, tried to measure the problem of over education with respect to the job mismatch (Betti and D'Agostino, 2011). Many factors can concentrate to acknowledge over education in literature because it can be complicated to measure the educational mismatch. They found that over education employment and cooperation agreements were mismatched with the dimensions of a work. They also found that female workers had greater degree of mismatch between their job and education owing to gender issue and environment of job place. Some researcher created a research on the graduate over-education and its effect (Battu and Sloane, 2012). For this purpose, they used two cohorts of graduates of the UK. They found that exist same relationship between extra qualification and work happiness. They also found that the impacts of over-education are most common in female employees than male graduate employees. Though it is puzzling which gender is more decumbent to overeducation. Also, performed a research on the over education among the graduates (Battu et al., 2006). They found that the job satisfaction and earnings played significant role for irrelevant jobs. Conducted a research to find the presence and uniqueness of educational mismatch in Italy (Cainarca and Sgobbi, 2009). For this purpose, they used the sample of 3600 Italian employees. The Italian cases were defined by the occurrence of under education over education and by constantly high levels of matching. In addition, the effects of gender, commercial business, or industry focus on other important aspects of the human capital that masks the inclusion of additional explanatory variables. Job competing models, while younger workers the wage equation shapes assignment model proved to be superior to other age groups. Young worker's examination of educational mismatch returned under penalty of overeducation relative and absolute ban confirmed indemnification undereducation. They found that undereducation and over education played significant role for irrelevant jobs.

\section{Methodology}

In this study, the target population is those who did fourteen and above year education, named as employed graduates in the administration department of University of Gujrat, Hafiz Hayat campus. The sample of 220 graduates is selected using simple random sampling technique from administration block out of 500 graduates. The entire record of administrative associates is accessible from SSIC branch of University of Gujrat. Well-structured questionnaire used as an instrument of data collection which was consist of five points scale for the determination of the factors causing the mismatch jobs after graduation. The multilayer perceptron neural network model has been used for analysis purpose. The reliability of questionnaire checked with the value of Cronbach's alpha is reported as 0.70 which is an estimate of true alpha.

\begin{tabular}{cc} 
Table 1 Test of Reliability \\
\hline $\begin{array}{c}\text { Cronbach's } \\
\text { Alpha }\end{array}$ & $\begin{array}{c}\text { Number } \\
\text { of items }\end{array}$ \\
0.70 & 22 \\
\hline
\end{tabular}

\section{Results and Discussion}

Table 2 showed the descriptive value of dependent variable of "nature of job". There are two category response irrelevant jobs which were $74.1 \%$ and Moderately Relevant jobs were 25.9\% out of 220 respondents. The neural network technique provides the set of connections associated with number of elements included in input, output and hidden layers. Information regarding input, hidden and output layers given in figure 4 , number no of units in the input layer are 37 and no of units in hidden layer are 2 and output layer also contains two units. From figure1 grey lines show positive weights and blue lines show negative weights. Nature of job is taken as dependent variable and resources, family responsibility, Family force, advertisement, distance, education, monthly income, marital status, age and gender are independents variable. Table 3 showed the model summary of training and holdout related to error and incorrect prediction of job mismatch. The error is very small in training sample percentage of incorrect prediction is .021 and in holdout incorrect prediction is .012 .

Table 2 Descriptive

\begin{tabular}{|c|c|c|c|}
\hline Statement & Irrelevant & $\begin{array}{c}\text { Moderately } \\
\text { Relevant }\end{array}$ & $\begin{array}{c}\text { Tota } \\
1\end{array}$ \\
\hline $\begin{array}{l}\text { How much your } \\
\text { current job is } \\
\text { relevant to your } \\
\text { areas of } \\
\text { education }\end{array}$ & $\begin{array}{c}163 \\
(74.1 \%)\end{array}$ & $\begin{array}{c}57 \\
(25.9 \%)\end{array}$ & $\begin{array}{r}220 \\
(10 \\
0 \%)\end{array}$ \\
\hline
\end{tabular}




\section{Table 3: Model Summary}

\begin{tabular}{llrr}
\hline Training & Cross Entropy Error & .021 \\
& Percent Incorrect & $.0 \%$ \\
& Predictions & \\
& Stopping Rule Used & Training error ratio criterion \\
& & $(.001)$ achieved & \\
& Training Time & $00: 00: 00.008$ \\
Testing & Cross Entropy Error & .012 \\
& Percent Incorrect & $.0 \%$ \\
& Predictions & \\
\hline Testing & Cross Entropy Error & .012 \\
& Percent Incorrect & $.0 \%$ \\
& Predictions & \\
\hline
\end{tabular}

Table 4 showed the classification results, in Neural Network Multilayer Perceptron analysis 164 cases were assigned to training sample and 56 cases to the hold out sample and total valid number of cases in this analysis are 220 . In training sample, the category irrelevant field of study classified correctly by $75.6 \%$ and category moderately relevant is correctly specified by $24.4 \%$. In holdout sample the category irrelevant field of study classified correctly by $66.1 \%$ and category moderately relevant is correctly specified by $33.9 \%$. Overall correctly classification for all categories is $100 \%$ due to above mentioned independent variables.

\section{Table 4: Classification}

\begin{tabular}{llccc}
\hline Sample & Observed & Predicted & & \\
\hline \multirow{2}{*}{ Training } & Irrelevant & Moderately & Percent \\
& & & Relevant & Correct \\
& Moderately & 0 & 0 & $100.0 \%$ \\
& Relevant & & 40 & $100.0 \%$ \\
Testing & Overall Percent & $75.6 \%$ & $24.4 \%$ & $100.0 \%$ \\
& Irrelevant & 37 & 0 & $100.0 \%$ \\
& Moderately & 0 & 19 & $100.0 \%$ \\
& Relevant & & & $100.0 \%$ \\
& Overall & $66.1 \%$ & $33.9 \%$ & \\
& Percentage & & & \\
\hline
\end{tabular}

Figure 1 and Table 5 shows the importance of the independent variables for the prediction of the dependent variable. There are ten variables which played the most important role for predicting the nature of job. This statistical technique has given highest importance to the availability of resources $100 \%$ importance rather than all other variables included in our analysis. Second important variable is family responsibility, third important variable is family force, forth is advertisement, fifth is distance, sixth is education, seventh is monthly income, 8th important variable is marital status, 9th important variable is age and 10th important variable is gender. The purpose of this research was to identify the factors which cause education-job mismatch so from the above results we can say that there is a need to develop such rules which would guarantee the exact scope of decent work. It is also necessary to improve the social relations between employers and employees so that they may satisfy to their jobs.

\section{Table 5 Independent Variable Importance}

\begin{tabular}{lc}
\hline Independent Variables & $\begin{array}{c}\text { Normalized } \\
\text { Importance }\end{array}$ \\
\hline Education level & $23.8 \%$ \\
Marital Status & $10.7 \%$ \\
Distance & $61.9 \%$ \\
Non availability of & $100 \%$ \\
resources & \\
Number of & $96.2 \%$ \\
dependence & \\
Advertisement & $82.5 \%$ \\
Family forced & $84.6 \%$ \\
Age & $15.7 \%$ \\
\hline
\end{tabular}

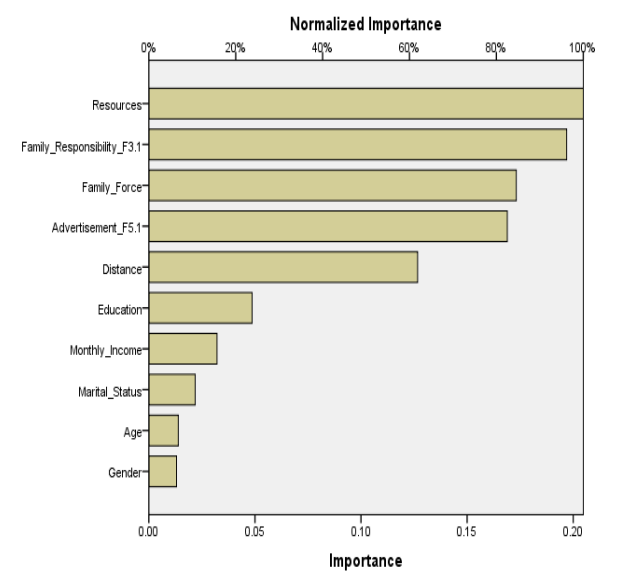

Fig. 1 
The chart displays in Figure 2 showed the ROC and two curves showed for each category. All the curves of these two categories are very close to upper left corner; which shows that our fitted model is better fit for this data and its cover the 1.000 area for irrelevant also same for moderately irrelevant. And figure 3 showed the lift chart here is curve match with base line which represented the best fit.
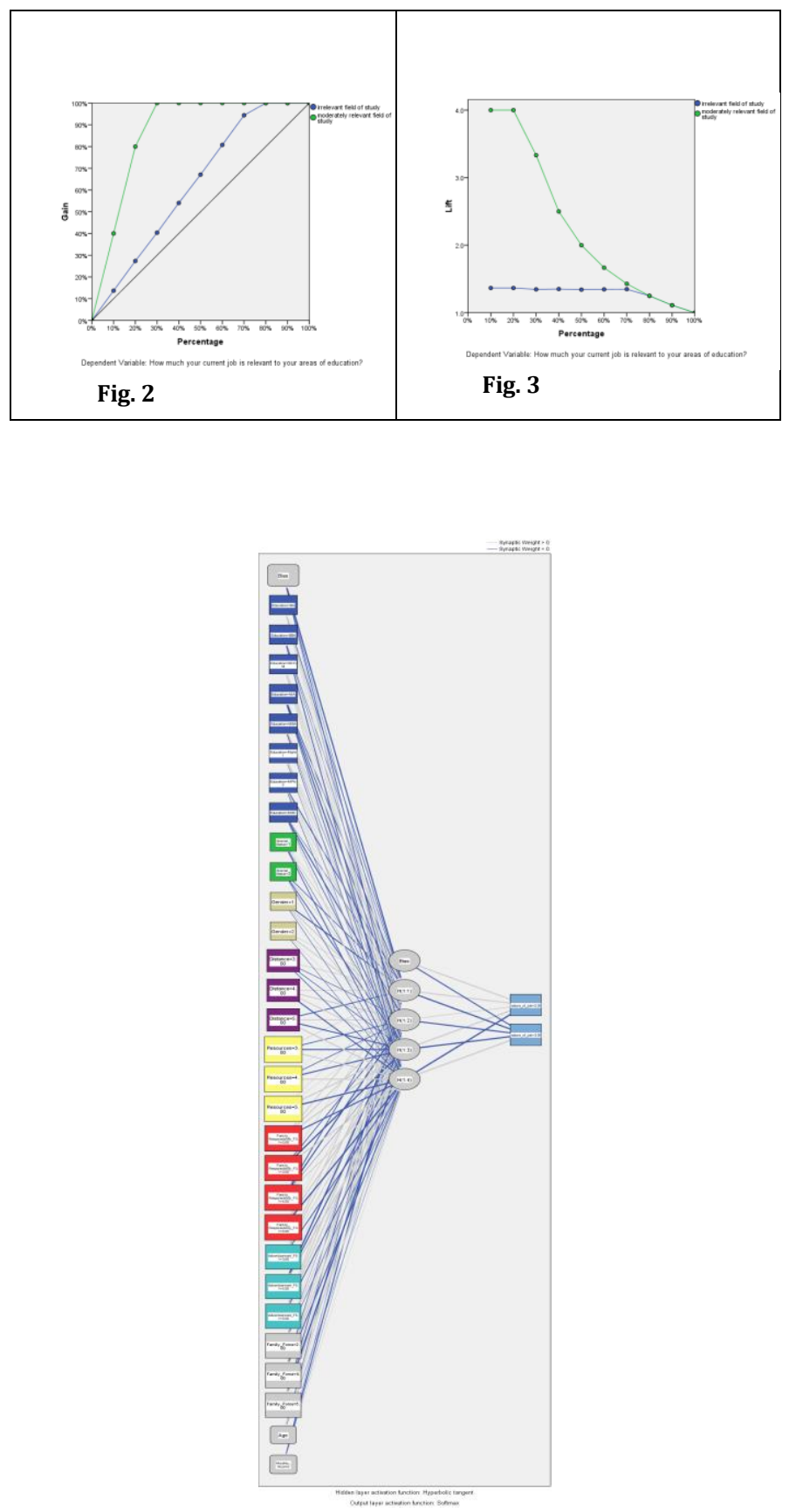

Fig. 4 Neural Network Diagram

\section{Conclusion}

In this research, we have exposed the inclinations of administrative staff (employees) for the factors which causes the education job mismatch after graduation to know the preference of the administrative staff members is an important task. To determine the important variables which caused irrelevant jobs after graduation we have been used neural networks models. The administrative staff more preferred the non-availability of resources as the important factor to do irrelevant job after their graduation. The other important variables which they preferred for the irrelevant job are family responsibility, family force, advertisement, distance between work place and residencies. Overall correct classification by the neural networks is $100 \%$.

\section{Recommendation}

In this study worked on administrative staff for the factors which caused mismatch job after graduation in University of Gujrat. In future, research may be conducted for large scale surveys like Labor Market, Telecommunication, and Hospital etc. 


\section{Reference}

[1] Allen, J., \& De Weert, E., (2007). What Do Educational Mismatches Tell Us About Skill Mismatches? A Cross-country Analysis. European Journal of Education, 42(1), 59-73.

[2] Allen, J., \& Van der Velden, R., (2001). Educational mismatches versus skill mismatches: effects on wages, job satisfaction, and on-the-job search. Oxford economic papers, 53(3), 434-452.

[3] Badillo-Amador, L., \& Vila, L. E., (2013). Education and skill mismatches: wage and job satisfaction consequences. International Journal of Manpower, 34(5), 416-428.

[4] Baert, S., Cockx, B., \& Verhaest, D., (2013). Overeducation at the start of the career: stepping stone or trap?. Labour Economics, 25, 123-140.

[5] Battu, H., Belfield, C. R., \& Sloane, P. J., (1999). Overeducation among graduates: a cohort view. Education economics, 7(1), 21-38.

[6] Battu, H., Belfield, C. R., \& Sloane, P. J., (2000). How well can we measure graduate over-education and its effects?. National Institute Economic Review, 171(1), 82-93.

[7] Berlingieri, F., \& Erdsiek, D., (2012). How relevant is job mismatch for German graduates?.

[8] Betti, G., D’Agostino, A. \& Neri, L. Soc Indic Res (2011) 103: 465. doi:10.1007/s11205-010-9712-6

[9] Brynin M., L Beate., and Longhi, S., (2006). Overqualification: Major or Minor Mismatches\|, ISER Working Paper, 17.

[10] Cainarca, G. C., \& Sgobbi, F. (2009). How Much Does it Pay? The Return to Education in Italy. Economia politica, 26(1), 53-84.

[11] Christina, B., Julian, L., Anja, R., and Andre, W., (2016). Overeducation - new evidence for 25 European countries, No 173, HWWI Research Papers, Hamburg Institute of International Economics (HWWI)

[12] Dekker, R., De Grip, A., \& Heijke, H. (2002). The effects of training and overeducation on career mobility in a segmented labour market. International Journal of Manpower, 23(2), 106-125.

[13] Farooq, S. (2011). Mismatch between education and occupation: A case study of Pakistani graduates. The Pakistan Development Review, 531-552.

[14] Farooq, S. (2015). Job mismatches in Pakistan: is there some wage penalty to graduates?. Pakistan Development Review, 54(2), 147.

[15] Green, F., \& McIntosh, S. (2007). Is there a genuine underutilization of skills amongst the over-qualified?. Applied economics, 39(4), 427-439.

[16] Green, F., McIntosh, S., \& Vignoles, A. (2002). The utilization of education and skills: evidence from Britain. The Manchester School, $70(6), 792-811$.

[17] Martin N., I. Persson, and Dan-Olof Rooth, (2008), "EducationOccupation Mismatch: Is there an Income Penalty?" , IZA Discussion Paper No. 3806.

[18] Peiró, J. M., Agut, S., \& Grau, R. (2010). The relationship between overeducation and job satisfaction among young Spanish workers: The role of salary, contract of employment, and work experience. Journal of Applied Social Psychology, 40(3), 666-689.

[19] Premji, S., \& Smith, P. M. (2013). Education-to-job mismatch and the risk of work injury. Injury prevention, 19(2), 106-111
[20] Robst, J. (2007). Education, college major, and job match: Gender differences in reasons for mismatch. Education Economics, 15(2), 159-175.

[21] Robst, John. "Education and job match: The relatedness of college major and work." Economics of Education Review 26.4 (2007): 397-407.

[22]

Rubb, S. (2003). Overeducation: a short or long run phenomenon for individuals?. Economics of education review, 22(4), 389-394. 